\title{
Premedication with clonidine before TIVA optimizes surgical field visualization and shortens duration of endoscopic sinus surgery - results of a clinical trial*
}

\author{
Katarzyna Wawrzyniak', Krzysztof Kusza',2, Jacek B. Cywinski³, \\ Pawel Krzysztof Burduk ${ }^{4}$, Wojciech Kazmierczak ${ }^{5}$ \\ ' Chair of Anesthesiology and Intensive Therapy Collegium Medicum in Bydgoszcz, Nicolaus Copernicus University of Torun, \\ Poland \\ ${ }^{2}$ Chair of Anesthesiology and Intensive Therapy Poznan Medical Science University, Poland \\ ${ }^{3}$ Department of General Anesthesiology, Cleveland Clinic, Cleveland, OH, USA \\ ${ }^{4}$ Chair of Otolaryngology and Laryngological Oncology Collegium Medicum in Bydgoszcz, Nicolaus Copernicus University \\ of Torun, Poland \\ ${ }^{5}$ Chair of Otolaryngology and Laryngological Oncology, Department of Pathophysiology of Hearing and Balance System \\ Collegium Medicum in Bydgoszcz, Nicolaus Copernicus University of Torun, Poland
}

Rhinology 51: 259-264, 2013

DOI:10.4193/Rhino12.174

*Received for publication:

October 12, 2012

Accepted: April 23, 2013

\section{Summary}

Background: During functional endoscopic sinus surgery (FESS), intraoperative bleeding can significantly compromise visualization of the surgical field. Clonidine constricts peripheral blood vessels and reduces systemic blood pressure, which in combination decrease nasal mucosa blood flow. This dual effect can potentially reduce bleeding during FESS and stabilize the intraoperative hemodynamic profile of the patient.

Aim: The aim of this prospective study was to assess if the quality of the surgical field visualization during FESS was improved when clonidine was used as a premedication agent.

Methodology: A group of 44 patients undergoing FESS for chronic sinusitis and polyp removal were enrolled and randomly assigned to receive either oral clonidine or midazolam as preoperative premedication. During the operation, the quality of the surgical field was assessed and graded by the operating surgeon using the scale proposed by Boezaart. The evaluations were done during surgery at 15 minutes (K1), 30 minutes (K2), 60 minutes (K3) and 120 minutes (K4) after incision.

Results: The duration of the surgical procedure was significantly shorter in the clonidine group: mean time of surgery: 80 vs. 96 min in the clonidine and midazolam groups, respectively. Also better quality of surgical field was observed at all time points in the clonidine group.

Conclusion: Premedication with clonidine before FESS results in shortening of the surgical time and a better quality of the surgical field.

Key words: clonidine, midazolam, anesthesia, endoscopic sinus surgery, surgical field

\section{Introduction}

Functional endoscopic sinus surgery (FESS) requires optimal surgical field visualization to reduce the incidence of surgical complications ${ }^{(1,2)}$. Major complications include: haemorrhage as 
a result of inadvertent injury to the ethmoid or sphenopalatine arteries, intraorbital or intracranial injury with cerebrospinal fluid leak as a result of accidental entrance into the orbital cavity or violation of the skull base. Most of these complications are related to inability to recognize anatomic boundaries of the operative area; therefore better visualization of the surgical field could potentially reduce the complication rate and improve outcomes $^{(2,3)}$.

Since FESS is performed on a highly vascularized area, various methods have been used to reduce bleeding and to optimize surgical field visibility during FESS performed under general anesthesia ${ }^{(1,2,4-6)}$. Some of the maneuvers to obtain a relatively bloodless field include: positioning the patient with the head up, injection and topicalization of nasal mucosa with vasoconstrictors, maintenance of deliberate, pharmacologically induced hypotension, preoperative steroid administration and use of total intravenous anesthesia (TIVA) $)^{(1-3,6-8)}$. However, it should be emphasized that none of the above mentioned methods or any combination thereof can guarantee an optimal surgical field ${ }^{(1,3)}$.

Clonidine is predominantly a centrally acting alpha2-agonist; however, it also has some peripheral alpha1-agonist activity as well, which may produce transient vasoconstriction. It was synthesized in the 1960s and although was originally tested as a nasal decongestant, nowadays it is used predominantly as an antihypertensive agent and adjuvant drug in anesthesia for its sedative and analgesic effects ${ }^{(1,9)}$. It seems that clonidine could reduce bleeding during FESS and stabilize the hemodynamic profile due to its central alpha2-agonist activity (inhibition of central sympathetic outflow), which results primarily in decrease of sympathetically mediated vasoconstriction, cardiac inotropy, and chronotropy ${ }^{(1)}$.

The aim of this study was to compare the intraoperative visualization and quality of the surgical field between two groups of patients who received either clonidine or standard midazolam premedication before TIVA for FESS.

\section{Materials and methods}

Between June 2008 and September 2009, we enrolled a total of 44 patients, aged 21-65 years, undergoing endoscopic sinus surgery for chronic sinusitis and polyp removal at the Department of Otolaryngology and Laryngological Oncology CM UMK. This prospective randomized study was approved by the Bioethics Committee of the Nicolaus Copernicus University (KB 171/2008) and written informed consent was obtained from all patients. Extent of chronic rhinosinusitis was graded according to the Lund-Mackay scale in all patients (based on preoperative computed tomography studies) ${ }^{(10)}$. Patients were randomly assigned using simple random sampling, to receive either oral clonidine (group I, $\mathrm{n}=22$ ) or midazolam (group II, $\mathrm{n}=22$ ) as a preoperative premedication. A similar surgical technique was used in all cases and consisted of removal of nasal polyps (in cases of polyposis) followed by middle meatal antrostomy, complete ethmoidectomy and frontal recess and sphenoid sinus surgery if necessary. All patients included in the study were physical status I or II according to the American Society of Anesthesiologists (ASA) classification.

Exclusion criteria included: significant cardiovascular disease, epilepsy, perceptive hearing loss, known allergy to clonidine, weight less than $50 \mathrm{~kg}$ or over $100 \mathrm{~kg}$, presence of malignant neoplasms, positive history of alcohol abuse, and pregnancy. Patients who received clonidine, benzodiazepines, neuroleptics or anti-depressants within two weeks prior to the surgery were excluded as well.

\section{Anaesthetic management}

All patients received $30 \mathrm{mg} /$ day of oral prednisolone acetate (Encorton, Polfa, Poland) for 7 days prior to the scheduled surgery, 60 to 90 minutes before induction of general anesthesia patients received orally either $3 \mu \mathrm{g} / \mathrm{kg}$ of clonidine (Iporel, Polfa, Poland) or $0.1 \mathrm{mg} / \mathrm{kg}$ of midazolam (Dormicum, Roche, Switzerland) according to randomization assignment. General anaesthesia was induced with remifentanil (Ultiva, Glaxo Wellcome, Great Britain) and propofol (1\% Plofed, Polfa, Poland) using target controlled infusion (TCl) pump (Orchestra Base Primea, Fresenius Kabi AG, Germany) based on the AAI (A-Line ${ }^{\mathrm{TM}}$ Autoregressive Index ${ }^{\mathrm{TM}}$ ) index and vekuronium (Norcuron, Organon, Holland) to facilitate endotracheal intubation. Intraoperatively standard non-invasive monitors were used (ECG, heart rate, noninvasive blood pressure: systolic SAP, diastolic DAP and mean $\mathrm{MAP})$, pulse oximetry $\left(\mathrm{SpO}_{2}\right)$, capnometry and capnography $\left(\mathrm{EtCO}_{2}\right)$ and electroencephalography (EEG) with acoustic brainevoked potentials (AEP/2, Danmeter, Denmark).

Intraoperatively, concentration of propofol was maintained at the level of $3 \mu \mathrm{g} / \mathrm{ml}$ using a TCl pump. Systemic blood pressure was controlled with adjustments of remifentanil infusion, however, if the incremental increase of remifentanil infusion rate was not sufficient to decrease MAP below $95 \mathrm{mmHg}$, bolus dose (10 mg) of urapidil (Ebrantil, Byk Gulden Lomberg, Germany) was administered intravenously. Intraoperative intravenous fluids consisted of $0.9 \% \mathrm{NaCl}$ solution given at the rate of $5 \mathrm{ml} /$ $\mathrm{kg} / \mathrm{h}$. The infusions of propofol and remifentanil were stopped at the end of the procedure during insertion of gauze tampons into the nose; each patient received intravenous infusion of paracetamol (1g Perfalgan, Bristol-Myers Squibb, Great Britain) for postoperative analgesia just before emergence from general anesthesia. All patients were awakened and extubated in the operating room at the completion of the surgery.

The following dosing regimen of hemostatic drugs (etamsylate/ tranexamid acid) was used in the postoperative period. After 
intravenous dose of $250 \mathrm{mg}$ etamsylate (Cyclolamine, Galena, Poland) a dose of $0,5 \mathrm{~g}$ of tranexamid acid (Exacyl, Sanofi-Aventis, France) three times was administered intravenously.

All patients were placed in a $20 \%$ reverse Trendelenburg position after induction of general anaesthesia and maintained in this position for the duration of the entire surgery. Before beginning of the surgical procedure, intranasally 2 doses of $0.5 \%$ oxymetazolin solution (Nasivin, Merck, Germany) were instilled into both nostrils of each patient. During the operation, the surgical field was graded in terms of bleeding by the operating surgeon using five-point scale proposed by Boezaart (from no bleeding: 1 to severe bleeding - constant suctioning required: 5) ${ }^{(11)}$.

Surgical field was evaluated intraoperatively at 15 minutes (K1), 30 minutes (K2), 60 minutes (K3) and 120 minutes (K4) after surgical incision. The study was conducted by one anaesthesiologist and two ENT surgeons; attending surgeons were blinded to patients' group allocation.

\section{Statistical analysis}

Data analysis was performed with Statistica v.8.0. (StatSoft, Poland). In statistical analyses Mann-Whitney test, Fisher's test, paired samples t-test were used as appropriate. For all tests, statistically significant level was set at $p<0,05$.

\section{Results}

Both analyzed groups were comparable in terms of the type and extent of performed surgical procedure. There were no significant differences in baseline characteristics between the groups (age, height, weight, gender and body mass index (BMI) and ASA status), descriptive statistics is presented in Table 1. In group I (clonidine group), the mean time of surgery was 80 minutes as compared to 96 minutes in group II (midazolam group) ( $p<0,001$, Table 2$)$.

There was a correlation between the type of drug used for premedication and the quality of surgical field at the first checked time point (K1): better quality of surgical field was observed in group I (95.45\% of patients had surgical field rated 1 or 2 on the Boezaart scale). In group II, $59.09 \%$ of the surgical field was rated 2 and none of the patients in this group had surgical field rated 1 on the Boezaart scale (Table 3 and Figure 1). At the second checked time point (K2), 95.45\% patients in group I had surgical field rated 1 or 2 as compared to only $13.64 \%$ rated 2 in group II (Table 3 and Figure 1). Better quality of surgical field in group I was also observed at the third checked time point (K3) as well. Subjectively, in the surgeon's opinion, grade 1 or 2 of the surgical field in the clonidine group (group I) was significantly better than in the midazolam group, $90.99 \%$ vs. $9.09 \%$ (Table 3 and Figure 1). The quality of the surgical field at the fourth checked time point (K4) was recorded as grade 4 and 5 only in
Table 1. Baseline characteristic of the study population.

\begin{tabular}{|c|c|c|c|c|}
\hline & $\begin{array}{l}\text { Study } \\
\text { group } \\
n=44\end{array}$ & $\begin{array}{c}\text { Clonidine } \\
\mathbf{n}=\mathbf{2 2}\end{array}$ & $\begin{array}{l}\text { Midazolam } \\
n=22\end{array}$ & p \\
\hline Gender (f/m) & $24 / 20$ & $11 / 11$ & $13 / 9$ & $0,549^{1}$ \\
\hline $\begin{array}{l}\text { Age (yers) } \\
\pm S D\end{array}$ & $48,6 \pm 7,7$ & $48,7 \pm 5,9$ & $48,5 \pm 9,4$ & $0,924^{2}$ \\
\hline $\begin{array}{l}\text { Height }(\mathrm{cm}) \\
\pm \mathrm{SD}\end{array}$ & $170,1 \pm 8,4$ & $170,4 \pm 7,6$ & $169,8 \pm 9,4$ & $0,834^{2}$ \\
\hline $\begin{array}{l}\text { Weight (kg) } \\
\pm \mathrm{SD}\end{array}$ & $70,9 \pm 13,1$ & $73,09 \pm 13,3$ & $68,6 \pm 12,8$ & $0,263^{2}$ \\
\hline $\begin{array}{l}\mathrm{BMI}\left(\mathrm{kg} / \mathrm{m}^{2}\right) \\
\pm \mathrm{SD}\end{array}$ & $24,3 \pm 0,3$ & $25,0 \pm 0,3$ & $23,6 \pm 0,3$ & $0,115^{2}$ \\
\hline
\end{tabular}

group II: it was observed in five patients from this group (Table 3 and Figure 1).

We also observed a significant correlation between type of premedication (clonidine vs. midazolam) and postoperative bleeding and the need for application of a haemostatic agent. In group I (clonidine), only one patient received a haemostatic drug, but 12 patients (54,54\%) in group II (midazolam) were treated postoperatively with haemostatic drugs (etamsylate/ tranexamid acid) (Table 2).

\section{Discussion}

Our investigation showed that premedication with clonidine in conjunction with TIVA significantly improved surgical conditions during FESS. This finding may have significant clinical implications and adds new knowledge to anaesthetic management strategies for FESS. Perioperative bleeding is a significant concern in FESS: major intraoperative bleeding compromises visualization of the surgical field and may result not only in prolongation of the operation but also may increase the incidence of surgical complications and compromise outcomes ${ }^{(1,2,12)}$. Administration of systemic steroids before surgery has been demonstrated to result in decreased intraoperative bleeding and better surgical field visualization in some reports ${ }^{(1,13)}$. It is conceivable that anaesthetic techniques, which allow tight control of the systemic blood pressure or induction of deliberate hypotension, can contribute to reduction of intraoperative blood loss simply by diminishing blood flow to the operated region. However, the relationship between intraoperative systemic blood pressure and the quality of the surgical field seems to be more complex: several studies showed that in fact active reduction of mean blood pressure below $70 \mathrm{mmHg}$ with vasodilators could cause 

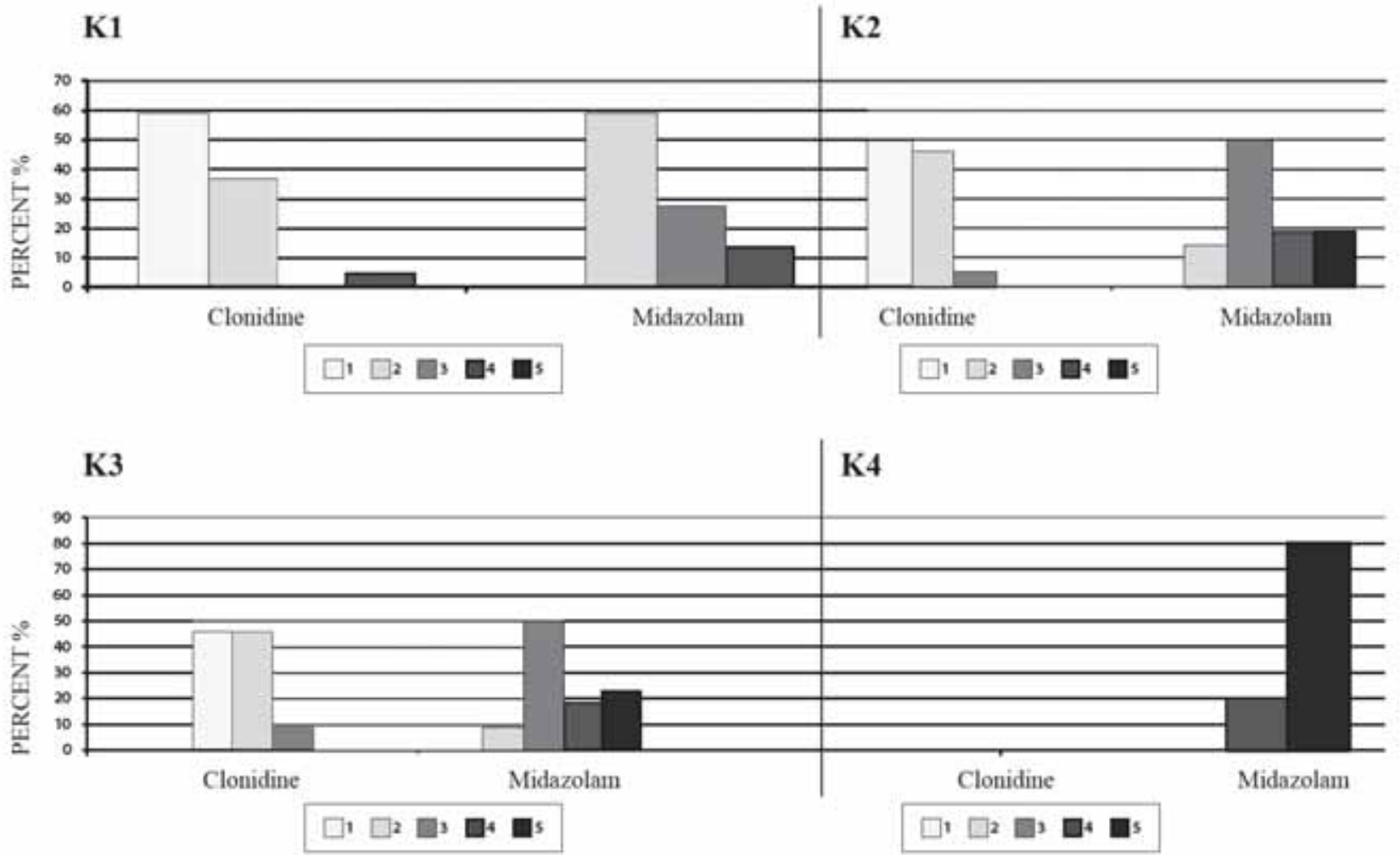

Figure 1. Percentage of patients (ordinate axis) in the scale of the quality of surgical field for the first (K1), second (K2), third (K3) and fourth time point checked (K4), depending on the premedication used. 1 - slight bleeding, no suction required, 2 - slight bleeding, occasional suction required, 3 - slight bleeding, frequent suction required, 4 - moderate bleeding, frequent suction required, 5 - severe bleeding, constant suction, surgery is not possible.

Table 2. The use of tranexamic acid / etamsylatum in the first 24 hours after surgery depending on the study group. Duration of surgery, depending on the type of premedication used.

\begin{tabular}{|c|c|c|c|c|}
\hline & \multicolumn{4}{|c|}{ Study drug } \\
\hline & $\begin{array}{c}\text { Study group } \\
\qquad n=44\end{array}$ & $\begin{array}{c}\text { Clonidine } \\
\mathbf{n}=\mathbf{2 2}\end{array}$ & $\begin{array}{c}\text { Midazolam } \\
n=22\end{array}$ & $\mathbf{p}$ \\
\hline $\begin{array}{l}\text { Surgery time } \\
\text { (min) } \pm S D\end{array}$ & $88,54 \pm 15,52$ & $80,45 \pm 10,45$ & $96,64 \pm 15,70$ & $<0,0001^{1}$ \\
\hline $\begin{array}{l}\text { tranexmic aci } \\
\text { etamsylatum }\end{array}$ & & & & \\
\hline Yes & 13 & $1(4,55)$ & $12(54,54)$ & \\
\hline No & 31 & $21(95,45)$ & $10(45,45)$ & \\
\hline
\end{tabular}

${ }^{1}$ Mann-Whitney test, ${ }^{2} \chi^{2}-$ test. major bleeding and worsen the quality of the surgical field. These observations were made with use of nitropruside sodium or phentolamine induced deliberate hypotension; presumably reflex tachycardia, and an increase in left ventricular stroke volume (as a response to vasodilatation) allowed more blood to extravasate into the surgical field ${ }^{(4,11)}$.

Clinical trials comparing surgical conditions achieved with inhalation anaesthesia and total intravenous anaesthesia (TIVA) during FESS seems to favor TIVA with propofol and remifentanil, since both agents synergistically decrease mean blood pressure and heart rate ${ }^{(5,7)}$. That in turn decreases cardiac output and reduces nasal blood flow, improving the surgical field ${ }^{(1,13)}$. Clonidine has gained popularity over the last 40 years mainly as an antihypertensive drug ${ }^{(14)}$. It seems that besides central alpha2 adrenergic receptors agonistic effect, it also affects peripheral alpha1 adrenergic receptors causing vasoconstriction. Administration of clonidine does not affect the baroreceptor reflexes but reduces its sensibility ${ }^{(15)}$ : it has been shown that administration of clonidine in NYHA III and IV patients did not cause cardiac depression or decrease cardiac output ${ }^{(15)}$. Clonidine has been used as a part of the premedication regimen 


\begin{tabular}{|c|c|c|c|c|c|c|c|c|}
\hline \multirow[t]{3}{*}{$\begin{array}{l}\text { Surgical } \\
\text { field K }\end{array}$} & \multicolumn{2}{|c|}{ K1 (after 15 min) } & \multicolumn{2}{|c|}{ K2 (after $30 \mathrm{~min}$ ) } & \multicolumn{2}{|c|}{ K3 (after $60 \mathrm{~min}$ ) } & \multicolumn{2}{|c|}{ K4 (after $120 \mathrm{~min}$ ) } \\
\hline & \multicolumn{2}{|c|}{ Study drug } & \multicolumn{2}{|c|}{ Study drug } & \multicolumn{2}{|c|}{ Study drug } & \multicolumn{2}{|c|}{ Study drug } \\
\hline & $\begin{array}{l}\text { Clonidine } \\
n=22(\%)\end{array}$ & $\begin{array}{l}\text { Midazolam } \\
n=22(\%)\end{array}$ & $\begin{array}{l}\text { Clonidine } \\
n=22(\%)\end{array}$ & $\begin{array}{l}\text { Midazolam } \\
\mathbf{n}=\mathbf{2 2}(\%)\end{array}$ & $\begin{array}{l}\text { Clonidine } \\
n=22(\%)\end{array}$ & $\begin{array}{c}\text { Midazolam } \\
n=22(\%)\end{array}$ & $\begin{array}{l}\text { Clonidine } \\
\mathbf{n}=22(\%)\end{array}$ & $\begin{array}{c}\text { Midazolam } \\
n=22(\%)\end{array}$ \\
\hline 1 & $13(59,09)$ & $0(0,00)$ & $11(50,00)$ & $0(0,00)$ & $10(45,45)$ & $0(0,00)$ & $0(0,00)$ & $0(0,00)$ \\
\hline 2 & $8(36,36)$ & $13(59,09)$ & $10(45,45)$ & $3(13,64)$ & $10(45,45)$ & $2(9,09)$ & $0(0,00)$ & $0(0,00)$ \\
\hline 3 & $0(0,00)$ & $6(27,27)$ & $1(4,55)$ & $11(50,00)$ & $2(9,09)$ & $11(50,00)$ & $0(0,00)$ & $0(0,00)$ \\
\hline 4 & $1(4,55)$ & $3(13,64)$ & $0(0,00)$ & $4(18,18)$ & $0(0,00)$ & $4(18,18)$ & $0(0,00)$ & $1(20,00)$ \\
\hline 5 & $0(0,00)$ & $0(0,00)$ & $0(0,00)$ & $4(18,18)$ & $0(0,00)$ & $5(22,73)$ & $0(0,00)$ & $4(80,00)$ \\
\hline$p$ & \multicolumn{2}{|c|}{$<0,0001^{1}$} & \multicolumn{2}{|c|}{$<0,0001^{1}$} & \multicolumn{2}{|c|}{$<0,0001^{1}$} & \multicolumn{2}{|c|}{$<0,0001^{1}$} \\
\hline
\end{tabular}

${ }^{1} \mathrm{~F}$ - Fisher's exact test.

because it provides mild sedative effect and blunts sympathetic response to laryngoscopy and tracheal intubation: clinical trials have demonstrated better stability of the cardiovascular system during tracheal intubation when clonidine was used in premedication versus placebo ${ }^{(16)}$ as well as decreases intraoperative bleeding in middle ear microsurgery ${ }^{(17)}$. Based on results of our study, it seems that additional benefit of clonidine premedication can be realized in patients undergoing FESS (e.g. improved quality of the surgical field).

In this prospective randomized study, we found that premedication with clonidine offers better quality of surgical field as well as better surgeon satisfaction during FESS. The vasoconstrictor effects of clonidine on nasal mucosa vessels allowed better visualization of the surgical field resulting in shorter duration of the procedure as well. Similar results were observed in two other clinical studies ${ }^{(3,18)}$. Hence, it seems that clonidine could be an attractive alternative to standard midazolam premedication in patients undergoing FESS $(19,20,21)$.

\section{Conclusion}

Clonidine, used in premedication before FESS, resulted in shortening of the surgical procedure, provided superior quality of surgical field, and significantly reduced the necessity to use haemostatic agents postoperatively. Premedication with clonidine seems to be a better alternative to midazolam in patients undergoing endoscopic sinus surgery.

\section{Acknowledgement}

The authors would like to thank the patients for taking part in this study.

\section{Authorship contribution}

KW: summarized the data of clinical trial and drafted the original article.

KK: summarized the data of anaesthesiology part of clinical trial JBC: re-written the original article

PKB: summarized the data of clinical trial

WK: summarized the discussion part of the manuscript

\section{Conflict of interest}

The authors declare that no competing interests exist. 


\section{References}

1. Mohseni M, Ebneshahidi A. The effect of oral clonidine premedication on blood loss and the quality of the surgical field during endoscopic sinus surgery: a placebocontrolled clinical trial. J Anesth. 2011; 25: 614-617.

2. Ahn HJ, Chung SK, Dhong HJ, Kim HY, et al. Comparison of surgical conditions during propofol or sevoflurane anesthesia for endoscopic sinus surgery. $\mathrm{Br} J$ Anaesthesia. 2008; 100: 50-54.

3. Wormald PJ. The surgical field in endoscopic sinus surgery. Endoscopic sinus surgery: anatomy, three-dimensional reconstruction and surgical technique. 2005, Thieme, New York: $\mathrm{p} 7-12$

4. Eberhart LH, Kussin A, Arndt C, et al. Effect of a balanced anaesthetic technique using desflurane and remifentanil on surgical conditions during microscopic and endoscopic sinus surgery. Rhinology. 2007; 45 : 72-78.

5. Eberhart LH, Folz BJ, Wulf H, Geldner G Intravenous anesthesia provides optimal surgical conditions during microscopic and endoscopic sinus surgery. Laryngoscope. 2003; 113: 1369-1373.

6. Tirelli G, Bigarini S, Russolo M, Lucangelo U, Gullo A. Total intravenous anesthesia in endoscopic sinus-nasal surgery. Acta Otorhinolaryngol Ital. 2004; 24: 137-144.

7. Wormald PJ, van Renen G, Parks J, Jones JA, Langton-Hewer CD. The effect of the total intravenous anesthesia compared with inhalational anesthesia on the surgical field during endoscopic sinus surgery. Am Rhinol. 2005; 19: 514-520

8. Baker AR, Baker AB. Anaesthesia for endo- scopic sinus surgery. Acta Anaesthesio Scand. 2010; 54: 795-803.

9. Okuyama K. The effects of prostaglandin E or oral clonidine premedication on blood loss during paranasal surgery. Can J Anesth. 2005: 52: 546-547.

10. Lund VJ, Mackay IS. Staging in rhinosinusitis Rhinology. 1993; 31: 183-184.

11. Boezaart AP, van der Merwe J, Coetzee AR Comparison of sodium nitroprusside and esmolol-induced controlled hypotension for functional endoscopic surgery. Can Anaesth. 1995; 42: 373-376.

12. Desborough JP. The stress response to trauma and surgery. Br J Anaesth. 2000; 85 109-117.

13. Sieskiewicz A, Olszewska E, Rogowski M Grycz E. Preoperative corticosteroid oral therapy and intraoperative bleeding during functional endoscopic sinus surgery in patients with severe nasal polyposis: a preliminary investigation. Ann Otol Rhinol Laryngol. 2006; 115: 490-494.

14. Hall D, Rezvan E, Tatakis D, et al. Oral clonidine pretreatment prior to venous cannulation. Anesth Prog. 2006; 53: 34-42

15. Kamibayashi T., Maze M. Perioperative use of alfa-2 adrenergic agonists. Curr Opin Anaesth. 1996; 9: 323- 327.

16. Matot I, Sichel JY, Yofe $V$, et al. The effect of clonidine premedication on hemodynamic responses to microlaryngoscopy and rigid bronchoscopy. Anesth Analg. 2000; 91: 828833.

17. Marchal JM, Gomez-Luque A, MartosCrespo F, et al. Clonidine decreases intraoperative bleeding in middle ear microsurgery. Acta Anaesthesiol Scand. 2001; 45: 627-633.
18. Jabalameli M, Hashemi M, Soltani $\mathrm{H}$ et al.: Oral clonidine premedication decreases intraoperative bleeding in patients undergoing endoscopic sinus surgery. J Res Med Sci. 2005; 10: 25-30.

19. Stevens RD, Burri $H$, Tramer MR. Pharmacological myocardial protection in patients undergoing noncardiac surgery: a quantitative systematic review. Anesth Analg. 2003; 97: 623-633.

20. Wallace AW: Clonidine and modification of perioperative outcome. Curr Opin Anaesthesiol. 2006; 19: 411-417.

21. Nair $S$, Collins $M$, Hung $P$, Rees $G$, Close $D$, Wormald PJ. The effect of $\beta$-Blocker premedication on the surgical field during endoscopic sinus surgery. Laryngoscope. 2004: 114: 1042-1046.

Katarzyna Wawrzyniak, M.D., Ph.D. Chair of Anesthesiology and Intensive Therapy Collegium Medicum in Bydgoszcz Nicolaus Copernicus University of Torun

Sklodowska-Curie 9

85-094 Bydgoszcz

Poland

Tel: +48-525-854 750

Fax: +48-525-854 022

E-mail:kwawrzyniak@wp.pl

\section{ERS-FELLOWSHIPS 2014 Sponsored by}

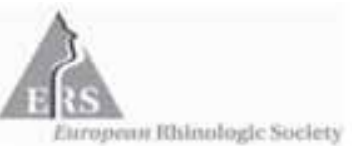

THE EUROPEAN RHINOLOGIC SOCIETY

Available to ERS-members from emerging European countries One place available on each of the following Courses in 2014

11th International Course in advanced Sinus Surgery Amsterdam, the Netherlands, March 27-28, 2014 Course Director: Prof. Dr. W.J. Fokken

Fax: +31205669573

Email: m.b.vanhuiden@amc.uva.n $15^{\text {th }}$ International Course on Reconstructive and Aesthetic Surgery of the Nose and Face "Around the Nose" Nijmegen, The Netherlands, June 11-13, 2014

Course Director: Dr. K. Ingel

Email: y.savelkoul-broekman@ pao.umcn.nl $46^{\text {th }}$ International Workshop on Functional and Endoscopic Sinus Techniques with Advanced Seminar

Graz, Austria, 2014, date to follow

Course Director: Prof. Dr. H. Stammberger

Email: claire.zwerina@meduni-graz.at
Endoscopic approach to Rhinosinusitis in Sinonasal Disease London, United Kingdom, 2014, date to follow Course Directors: Prof. V.J. Lund

Fax: +44 02078379279

Email: sarah.harris@ucl.ac.uk]

$21^{\text {th }}$ Rhinoplasty Course (International Course in Modern

Rhinoplasty Techniques)

Amsterdam, The Netherlands, 2014, date to follow

Course Director: Dr. Menger

Email: m.b.vanhuiden@amc.uva.nl

Sponsorship comprises a sum of 1200 Euro to assist in both registration fees and costs of ccommodation/travelling. More information and application forms are available on the website:

http://www.europeanrhinologicsociety.org

Applications should be submitted before February 1, 2014. For questions you can contact:

Judith Kosman, Secretary ERS, rhinologysecretary@amc.nl

Applicants should be under the age of 40 years without former granting of an ERS-fellowship. 